\title{
A survey study of the level of pesticide residues in Egyptian exports of vegetables for the period 2015-2019, based on the RASFF database
}

\author{
Tarek Abd El-Alieem Abd El-Rahman * \\ Pesticide Residues and Environmental Pollution Department, Central Agricultural Pesticide Laboratory, Agricultural \\ Research Center, Dokki, Giza 12618, Egypt.
}

Publication history: Received on 29 September 2020; revised on 22 October 2020; accepted on 24 October 2020

Article DOI: https://doi.org/10.30574/gscarr.2020.5.1.0082

\begin{abstract}
Egypt is one of the countries that depend on the export of vegetables and fruits to European Union countries. It follows the procedures imposed by those countries from the organized RASFF that sets special conditions for the quality of those products. Some of the restrictions set by RASFF are concerned with pesticide residues in vegetables and fruits. In this study, data on Egyptian exports of vegetables tracked from the RASFF database organized from 2015 to 2019.

The results showed that, about 52 samples banned from the Egyptian exports of vegetables during the period from 2015 to 2019 were due to the high levels of pesticide residues viz: the maximum residues limits.The highest frequent samples under study recorded in the year 2015 at 46.15\%, followed by year 2016 and 2017 reaching 21.5\%. While the lowest recorded, years were 2018-2019 (5.77 and $3.85 \%$ ), respectively. Twenty-four active ingredients recorded in the samples under study. The most detected pesticide groups were insecticides (50\%) followed by fungicides (37.5\%). All samples were free from any detectable residues of herbicidal active ingredients. While recording, propargite was the highest incidence of samples with $14.46 \%$ followed by chlorpyrifos, methomyl, and flusilazole, with percentage frequencies of $12.05 \%, 10.84 \%$, and $9.64 \%$, respectively. Fourteen out of twenty-four active ingredients registered in the state of Egypt, with the percentage of $58.33 \%$. The percentage of not registered pesticides was $33.33 \%$ and $8.32 \%$ of restricted pesticides use ,of the findings as well as the pesticides revoked by Egyptian authorization.
\end{abstract}

Keywords: Pesticide residues; Egyptian exports of vegetables; RASFF

\section{Introduction}

Fruits and vegetables are important components of the human diet since they provide essential nutrients that are required for most of the reactions occurring in the body (Attia 2016). Exports of agricultural crops play an important role in economic development given the promising contribution to the country's earnings of foreign currencies. For Egypt, vegetables come on top of the agricultural export crops that provide the foreign currencies required to close the deficit in the balance of trade and agriculture. Potatoes and onion have been selected in this research because they represent $42.1 \%$ of the total value of vegetable exports that amounted to US\$ 980 million over the period (20102014).Egypt is an important trade partner for the export of vegetable to the EU. According to information from the Foreign Trade Data Warehouse - General Organization for Export and Import Control in Egypt, the volume of foodstuffs of plant origin exported to the EU reached 368.057 tons in 2009. The main production areas are Ismailia, El-Behira, and El-Menofia governorates (Attia 2016). Egypt released statistics of annual Egypt's exports of vegetables and fruits to the European Union twenty-seven countries during the period from 2015 to 2019, recording (133.428, 133.622, 161.134, 164.715 and 210.457 tons), respectively (GOEIC 2020).

\footnotetext{
${ }^{*}$ Corresponding author: Tarek A. Abd El Rahman

Pesticide Residues and Environmental Pollution Department, Central Agricultural Pesticide Laboratory, Agricultural Research Center, Dokki, Giza 12618, Egypt.
} 
The RASFF (The Rapid Alert System for Food and Feed) was put in place to provide food and feed control authorities with an effective tool to exchange information about measures taken responding to serious risks detected in relation to food or feed. This exchange of information helps member states to act more rapidly and in a coordinated manner in response to a health threats caused by food or feed. Its effectiveness is ensured by keeping its structure simple: it consists essentially of clearly identified contact points in the Commission, (EFSA and EFTA) and at national level in member countries, exchanging information in a clear and structured way by means of templates. (RASFF 2016).

Egyptian exports of fresh vegetables have suffered from the European Union's rejection of the borders in the past few years. Due to violations of the European Union pesticides limits (MRLs) and the European Union rapid alert system. The Food and Feed Authority (RASFF) reported some rejected cases of fresh vegetables imported from Egypt during 2019/2015. The European Union introduced Egyptian exports of vegetables such as pepper to increase the level of control (EC No. 1021/2014) (Attallah 2016).

Plant protection products PPP (more commonly known as pesticides) are widely used in planting and storage phases to increase yield, fight pests, improve quality and extend the life of food crops (Fernndez-Alba and Garca-Reyes 2008). Pesticide residue is a decisive and influencing factor to allow shipments of agricultural products to enter importing countries, especially European Union countries. Vegetable plants are susceptible to infestation with various pests that cause severe damage. Therefore, the chemical control represents the major method in this respect and hence pesticides have played a significant role in increasing agricultural crops in both quantity and quality. Although such pesticides used as recommended, small amounts may be found on or in treated crop at harvest (Ministry of Agriculture 2020). (Abd-El Rahman 2016).

Therefore, this study based on the RASFF database aims to use statistical analysis to determine the status of the level of pesticide residues in Egyptian vegetable products exported during the period 2015-2015, specifically by the most important active ingredients of pesticides that cause problems affecting Egyptian exports, especially vegetables. Tracking the position of these active ingredients in terms of their registration in Egypt is explored. The main candidate categories for further interpretation of risk category, notification classification, basis of notification, actions taken and risk decision.

In light of the results obtained, appropriate solutions to reduce or limit the problems with pesticide residues are a final suggestion action to reduce the levels of those vehicles.

\section{Material and methods}

\subsection{Data collection}

Data on the pollution of pesticide residues during the period 2015-2019 collected through the website of the European Union RASFF Portal. Search criteria for RASFF notifications for Egyptian vegetables exported to the European Union were from 01/01/2015 until 31/12/2019. Product category "vegetable" and category "Hazard pesticide residues Country" flagged as Origin and Country Egypt (Fig.1) (Lüth et al. 2019).

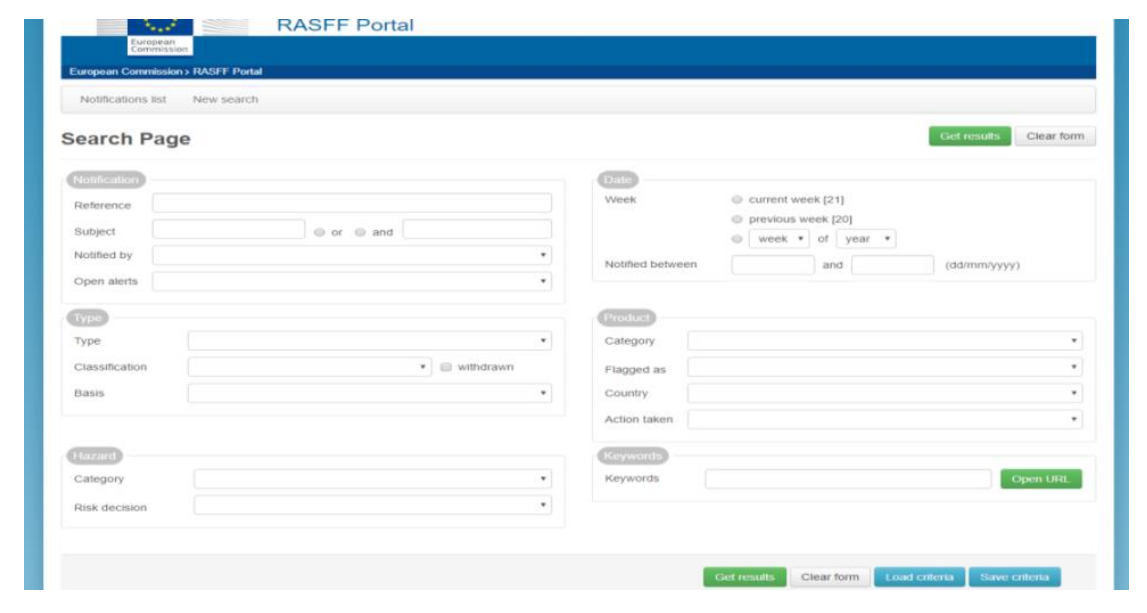

Figure 1 Website of the European Union RASFF Portal 


\subsection{Statistical analysis}

Subsequent database has been processed through Microsoft Excel 2010 (Microsoft Corp., Redmond, USA) to produce descriptive statistics, including frequency distributions (for the crops being studied as well as pesticide residues). The main candidate categories for further interpretation of pesticides residues data were the date (by year), risk category, notification classification, basis of notification, actions taken and risk decision. The position of the active substances of pesticide residues in terms of registration in the Egyptian database, as well as the classification of those active substances in terms of use and toxicity was reported by (Lüth et al. 2019).

\section{Results and discussion}

The RASFF is one of the organizations that determine the path of exports to the European Union in terms of quality of products. Determination of pollution levels and the degree of acceptance or rejection of these products is of concern. The diversity of these pollutants is between biological pollutants such as fungi, bacteria, viruses and aflatoxins, and chemical pollutants such as pesticides residues and heavy metals in addition to other pollutants.

Data in (Table.1 and Fig.2) show that, the RASFF's database. 52 samples of representing 8 vegetables received from Egypt were studied and rejected by the RASFF during the period from 2015 to 2019. The highest percentage frequencies of samples under study in year 2015 recorded $46.15 \%$, followed by year 2016 and 2017 reached $21.5 \%$, while the lowest year's were 2018-2019 recorded 5.77 and $3.85 \%$, respectively.

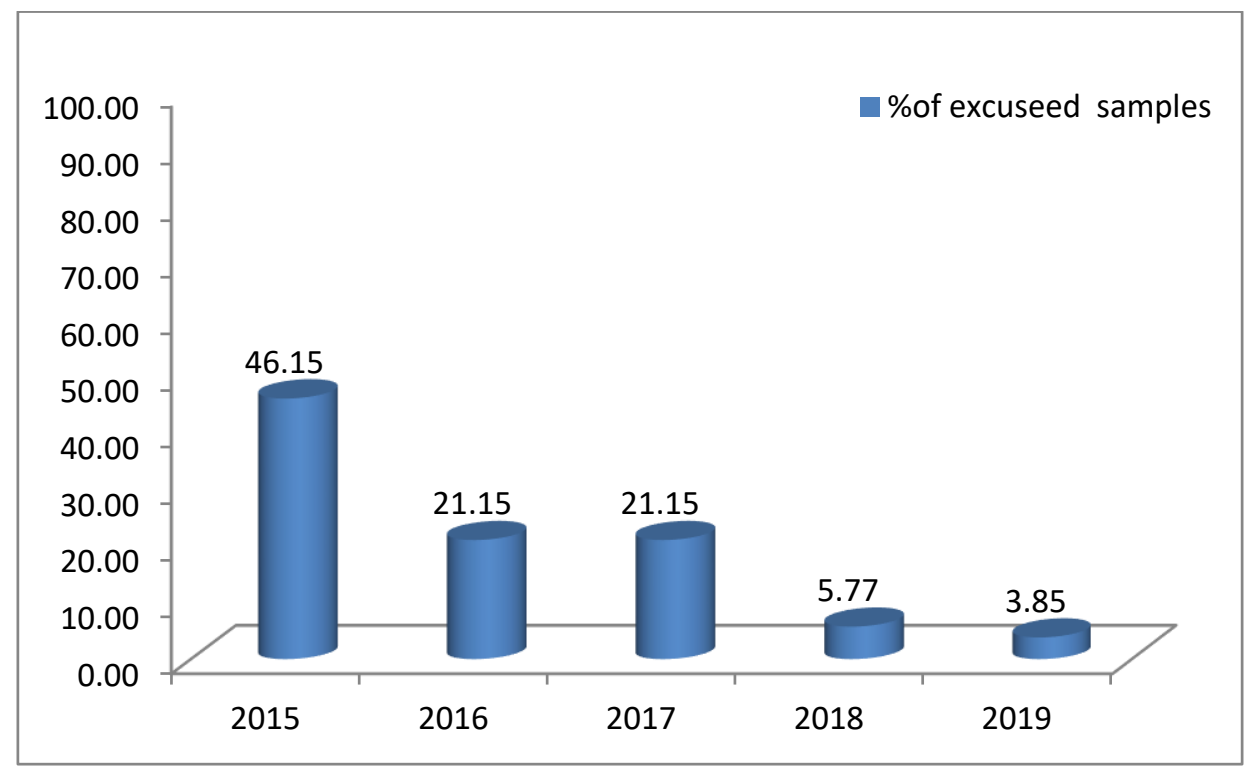

Figure 2 Percentage of excused samples during the period 2015-2019

\subsection{The violated Egyptian exports of vegetable samples for the period 2015-2019, based on the RASFF database}

\subsubsection{Evaluation of vegetable commodities during the period 2015-2019:}

Data in (Table 1 and Fig.3) show that, the RASFF's database during the year 2015, 25 Egyptian exports of vegetable samples exceeded the maximum limits, and their percentage frequencies was $46.15 \%$ of all samples in the RASFF's database during the period 2015-2019. Representing five vegetable commodities (artichokes, cucumbers, mix chilies, peppers, and strawberries) .Peppers commodity samples the most contaminated in the studied samples followed by strawberries, their percentage frequencies were $48 \%$ and $40 \%$, respectively. While the lowest commodities artichokes, cucumbers, and mix-chilies and were their percentage frequencies $4 \%$. During the year 2016, 11 Egyptian exports of vegetable samples exceeding the maximum limits representing three vegetable commodities (fresh green beans, peppers, and strawberries). Pepper commodity samples were the most contaminants in the study samples followed by strawberries, their percentage frequencies were (54.54\% and $36.36 \%)$, respectively. While the lowest commodity fresh green beans and it is percentage, frequency was $9.09 \%$. In year 2017, a total of 11 Egyptian exports of vegetable samples exceeding the maximum residues limits were found, representing 5 vegetable commodities (cucumbers, frozen vine leaves, tomatoes, strawberries and peppers).Pepper commodity samples were the most contaminated in the 
studied samples followed by tomatoes, their percentage frequencies were $(45.45 \%$ and $27.27 \%)$, respectively. While the lowest commodities (cucumbers, frozen vine leaves, and strawberries) and their percentage frequencies were, 9.09 $\%$ during the year 2018. Three Egyptian exports of vegetable samples exceeding the maximum limits were found in peppers. In year 2019, two Egyptian exports of vegetable samples exceeding the maximum limits in peppers and strawberries.

Result Data in (Table. 1 and Fig. 3) show that, the RASFF's database, during 2015-2019, a total of 52 Egyptian exports of vegetables samples exceeding the maximum residue limits, representing 8 vegetable commodities (artichokes, cucumbers, frozen vine leaves, frozen green beans mix chilies, peppers, tomatoes and strawberries). Peppers and strawberries, commodities samples were the most contaminants in the study samples, their percentage frequencies were (51.92\% and $30.77 \%$ ), respectively, followed by tomatoes and cucumbers, reached to $5.77 \%$ and $3.85 \%$, respectively. While the lowest commodity was (artichokes, mix chilies frozen vine leaves, frozen green beans) found and their percentage frequency was $1.92 \%$.

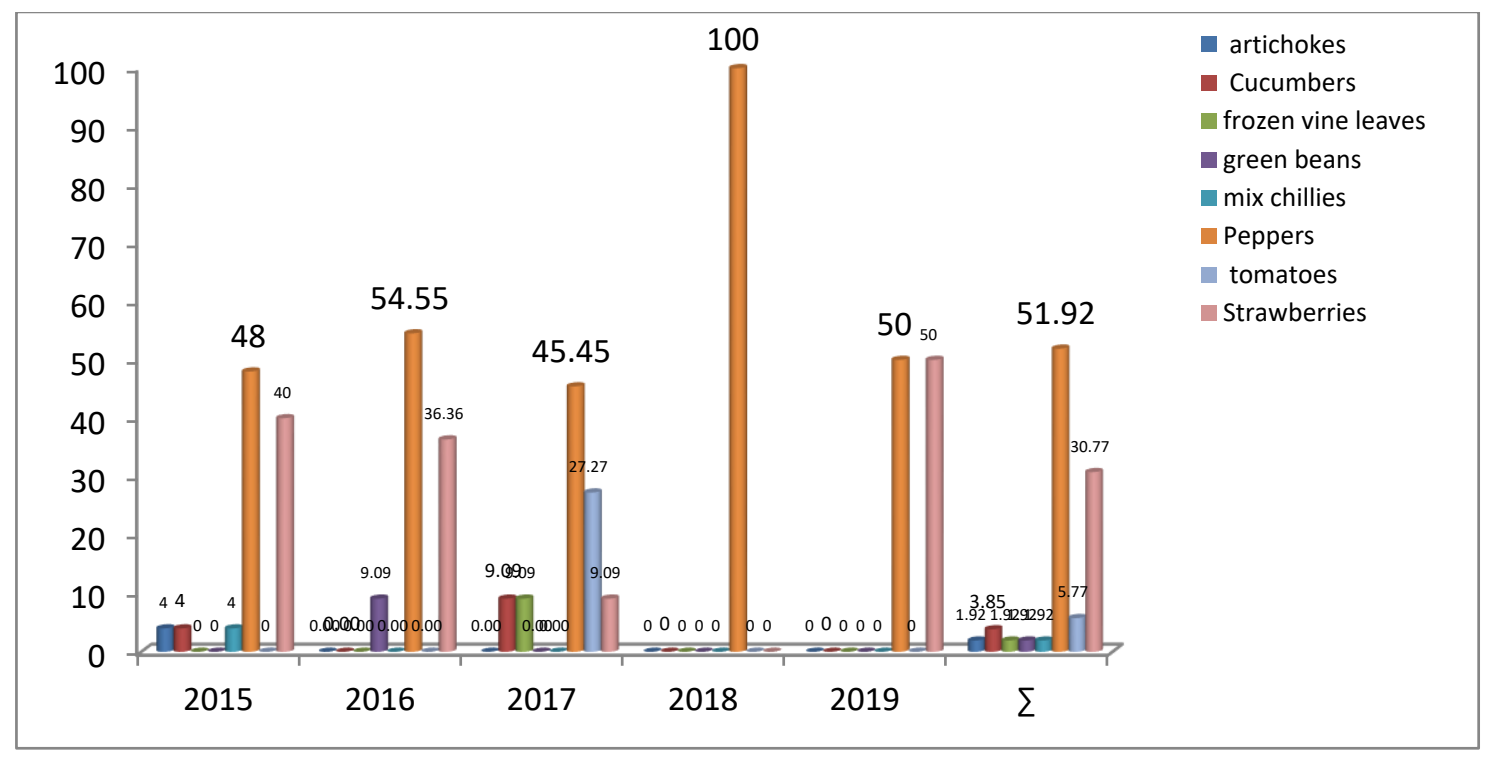

Figure 3Percentage of each vegetable contamination with pesticide residues during the period 2015-2019

\subsubsection{Evaluation by active ingredients and commodities during the period 2015-2019:}

Data in (Table 1) demonstrated the levels of pesticide residues in five vegetable commodity samples in 2015. Strawberry samples were the most contemned by ten different active ingredients and their registration situation in Egypt by Agriculture Pesticide Committee (APC) such as: not registered (fipronil, pyridalyl, propargite) and registered \& not recommended (chlorpyrifos, cyfluthrin, dinotefuran, dimethoate, methomyl, propamocarb and oxamyl). Followed by pepper samples, in which five active ingredients were detected, were not registered (flusilazole and carbendazim) and registered \& not Recommended (dinotefuran, dodine and methomyl). Two pesticides registered \& not recommended detected in mix chili samples (lambda-cyhalothrin and oxamyl), while in artichokes, cucumbers samples carbendazim and procymidone active ingredient (not registered) detected, respectively.

(Fig.4) shows the percentage registration situation of active ingredients in Egypt by Agriculture Pesticide Committee (APC) during 2015, the highest contaminated in the studied samples and were registered\& not recommended for the pesticides found in 5 vegetable commodity samples with percentage frequency of $63.51 \%$, followed by not registered, their percentage frequency of $36.84 \%$. While all the samples studied in 2015 were free from any residues (registered \& recommended).

Data in (Table. 1) demonstrated the level of pesticide residues in three vegetable commodity samples during 2016. Pepper samples detected by seven active ingredients such as oxamyl, methomyl, lambda-cyhalothrin, chlorpyrifos (registered\& not recommended) propargite, carbendazim and carbofuran (not registered). Followed by strawberry samples, which were contaminated by five different active ingredients such as propargite was (not registered) and (registered \& not recommended) as methomyl, profenofos, dimethoate and oxamyl, while fresh green bean samples were detected by only active ingredient propargite (not registered). 
(Fig.4) shows the \% of registration situation of active ingredients in Egypt by Agriculture Pesticide Committee (APC) during 2016, the highest contaminants in the study samples was \% of registered \& not Recommended of pesticides found in 3 vegetable commodities samples was $60 \%$, followed by not registered, their percentage frequencies were $40 \%$. On the other hand, all simple studied in 2016 were free from any residues of registered\& recommended.

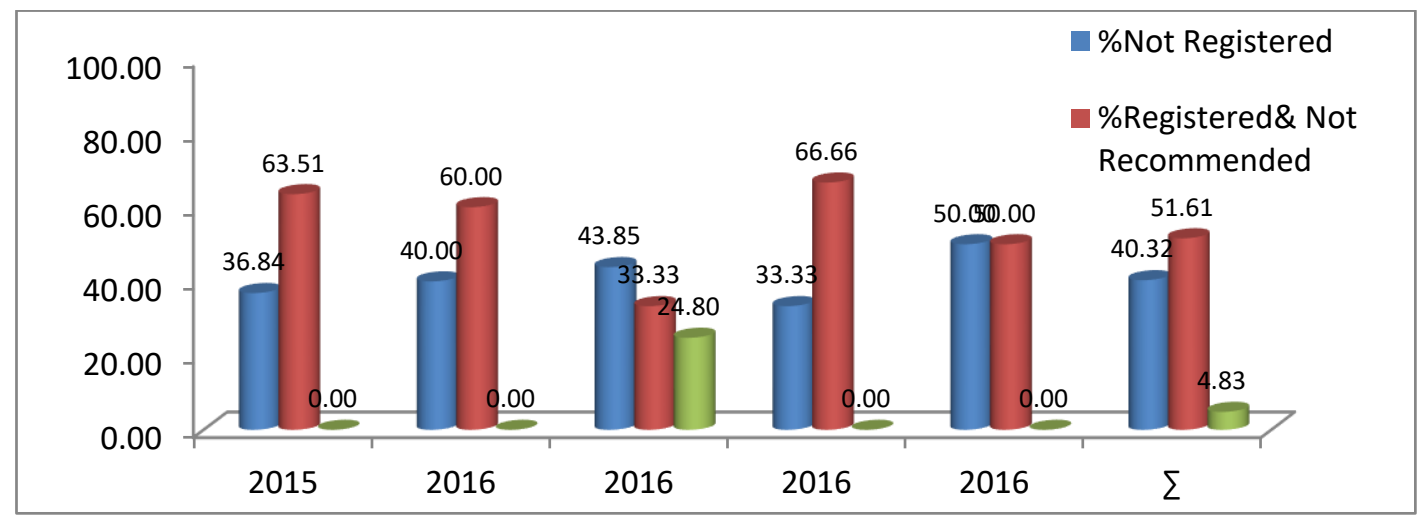

Figure 4 Percentage of Registration situation of active ingredients in Egypt.

Data in (Table 1) demonstrated the level of pesticide residues in five vegetable commodities samples in 2017. Pepper samples were the most contaminants by nine different active ingredients such as methamidophos, propargite, flusilazole and carbofuran (not registered and registered \& not recommended), methomyl, chlorpyrifos, propiconazole, chlorfenapyr lambda-cyhalothrin, followed by contaminated frozen vine leaves by eight different active ingredients such as acetamiprid ,lambda-cyhalothrin (registered\& not recommended), azoxystrobin, myclobutanil and propiconazole (registered \& recommended) and carbendazim, diniconazole and flusilazole (not registered). While tomato, strawberry and cucumber samples were detected by one active ingredient was chlorpyrifos, (registered\& recommended), methamidophos and procymidone (not Registered), respectively.

(Fig. 4) shows the \% registration situation of active ingredients in Egypt by Agriculture Pesticide Committee (APC) during 2017, the highest contaminated studied samples was \% of not registered pesticides found in 5 vegetable commodity samples was $43.85 \%$ followed by registered \& not recommended and registered \& recommended with percentage frequencies of $33.33 \%$ and $24.80 \%$, respectively.

Three samples of peppers were contaminated by three pesticides in 2018 (carbofuran, not registered), chlorpyrifos and methomyl (registered\& not recommended).

(Fig.4) shows, the \% registration situation of active ingredients in Egypt by Agriculture Pesticide Committee (APC) during 2018, the highest contaminants in the studied samples with \% of (registered \& not recommended) pesticides found in peppers samples was $60 \%$, followed by not registered, their percentage frequencies were $40 \%$. All samples studied in 2018 were free from any residues of registered \& recommended.

(Fig. 4) shows the percentage registration situation of active ingredients in Egypt by Agriculture Pesticide Committee (APC) during 2019, found in two vegetable commodity samples with 50\%, percentage of registered \& not recommended and not registered, while all samples studied in 2019 were free from any residues of registered \& recommended. Two pesticides (chlorpyrifos was registered \& not recommended and propargite was Not Registered) detected in pepper samples, on the other hand, oxamyl detected in strawberry samples.

The results in (Fig .4) obtained from 52 samples were contaminated with 62 pesticides, representing 24 active substances that differ in classification in terms of registered or unregistered and are these pesticides registered and recommended on the same crop by comparing them with the database of (APC 2020). The highest classification of registered and recommended recorded was 51.61\%, followed by unregistered classification 40.32\%, while classification registered and recommended was $4.83 \%$.

\subsubsection{Evaluation by risk category, risk decision, notification classification, basis of notification and actions taken during the period 2015-2019.}

A package of main measures taken towards these samples (52), taken by the RASFF's during the year 2015 to 2019 , for example (Decision risk, action taken and notification type). Their decision risks were varied in terms of sub-decisions 
such as :serious, not serious and undecided, \% destruction, \% import not authorized, \% informing authorities, \% official detention, \% re-dispatch and \% placed under customs seals and border rejection, alert and information for attention, respectively.

Data in (Table 1) demonstrated a number of measures taken towards the 25 samples during 2015 such as artichoke, cucumber and mix chili samples, as follows: decision risk was undecided, while actions taken were official detention, informing authorities, destruction, respectively. In addition, notification type (border rejection, information for attention and border rejection, respectively). About 12 samples of peppers decision risk were six undecided, four serious, and two not serious samples, respectively. While action taken to 12 samples of peppers were (five official detention, one informing authorities, six destruction samples), respectively. In addition, the notification type was border rejection in all samples of peppers. Ten samples of strawberries (decision risk) were three undecided, one serious and six not serious samples, respectively. While action taken 10 samples of peppers were four imports (not authorized, two placed under customs seals, 4 destruction samples, respectively). Moreover, the notification type was border rejection in all samples of strawberries. (Fig.5) show that, the percentage decisions risk were varied in terms of sub-decisions such as serious, not serious and undecided, in samples during 2015 were (20\%, 32\% and 48\%), respectively. (Fig.6) indicted that, percentage of action taken were \% destruction, $\%$ import not authorized, $\%$ informing authorities and $\%$ official detention of excused samples during the period 2015 and were (44\%,16\%,8 \%,24 \% and 8\%), respectively. (Fig.7) demonstrated the Percentage of notification type (percentage border rejection and percentage information for attention) of excused samples during the period 2015, and was ( $96 \%$ and $4 \%$ ), respectively.

Data in (Table 1) demonstrated, decision risk and action taken to samples in year 2016. Fresh green beans were undecided and official detention, respectively. About six samples of peppers were decision risk and action taken, five serious and undecided and import not authorized two destruction, two official detention, and re-dispatch samples, respectively. Four samples of strawberries were decision risk, two undecided, and two serious samples, respectively. While action taken were three import not and destruction samples, respectively. Moreover, the notification type was border rejection in all samples of fresh green beans, peppers, and strawberries. (Fig.5) shows that, the percentage decisions risk were varied in terms of sub-decisions such as serious, not serious and undecided, in samples during 2016 and were (81.82\%, 0\% and 18.18\%), respectively. (Fig.6) indicted that percentage of action taken (\% destruction, \% import not authorized, \% official detention and \% re-dispatch) of excused samples during the period 2015 were $27.27 \%, 36.36 \%, 27.27 \%$ and 9.09\%, respectively. (Fig.7) demonstrated the percentage of not fictional type samples and percentage border rejection of excused samples during the period 2016.

Result in (Table 1) demonstrated samples of cucumbers, frozen vine leaves and strawberries were taken by the RASFF's database during the year 2017, for example decision risk, action taken were serious, not serious and undecided, redispatch, destruction and import not authorized, respectively. The notification type was border rejection in all samples of cucumbers, frozen vine leaves, and strawberries. While all samples of tomatoes recorded decision risk was serious, action taken were official detention, destruction and placed under customs seals and notification type was 2 border rejection and alert. All samples of peppers (Decision risk and notification type) were serious and border rejection, respectively. While actions taken about samples of peppers show what're-dispatch 2, destruction, placed under customs seals and return to consignor). (Fig.5) shows that, the percentage decisions risk were varied in terms of sub-decisions such as serious, not serious and undecided, in samples during 2017 and were (81.82\%, 9.09\% and 9.09\%), respectively. (Fig.6) indicated that the Percentage of action taken (\% destruction, \% import not authorized, \% official detention, \%redispatch and \% placed under customs seals) of excused samples during the period 2015 were $(27.27 \%, 9.09 \%, 9.09$ $\%, 18.18 \%, 27.27 \%$ and 9.09\%), respectively. (Fig.7) demonstrated the percentage of notification type and was percentage of border rejection, and alert of excused samples during the period 2017 were (99.91\% and 9.09\%) respectively.

Data in (Table. 1) demonstrated that all samples of peppers (Decision risk, actions taken and notification type) were serious, import not authorized, destruction, and border rejection, respectively. All samples of peppers (Decision risk and notification type) were serious and border rejection, respectively. While actions taken about samples of peppers show two destructions, import not authorized, respectively. (Figs 5 and 7) show all samples in 2018. The \% decisions risk and notification type were varied in terms of sub-decisions such as: serious and border rejection 100\% (Fig. 6) indicted that percentage of action taken were \% destruction \% import not authorized of excused samples during the period 2018 and were (66.66 and 33.33\%), respectively.

Data in (Table 1) demonstrated that all samples of peppers and strawberries (Decision risk and actions taken) were serious and destruction, respectively. While notification type of pepper and strawberry samples were information for attention and border rejection, respectively. All samples in 2019 (percentage decisions risk) varied in terms of subdecisions such as: serious 100\%. Figures 5 and 6 show that all samples in 2019 (percentage decisions risk and action taken) were varied in terms of sub-decisions such as percentage serious and percentage destruction, respectively. (Fig. 7) demonstrated the percentage of notification type were percentage border rejection and percentage information for attention of excused samples during the period 2019 and were $50 \%$ and $50 \%$, respectively.

(Figs .5 , 6 and 7) show that the percentage of decision risk (\% serious, \% not serious and \% undecided) of excused samples during the period 2015-2019 were 53.85\%,17.31\% and 28.85\%, respectively. While the Percentage action 
taken (\% destruction, \% import not authorized, \% informing authorities, \% official detention, \% re-dispatch and \% placed under customs seals) were 40.38\%,19.23\%,3.85\%,19.23\%,7.69\%,7.69\% and $1.92 \%$, respectively. The percentage of notification type (percentage border rejection, percentage alert and percentage information for attention) were $(94.23 \%, 1.92 \%$ and $3.85 \%)$, respectively.

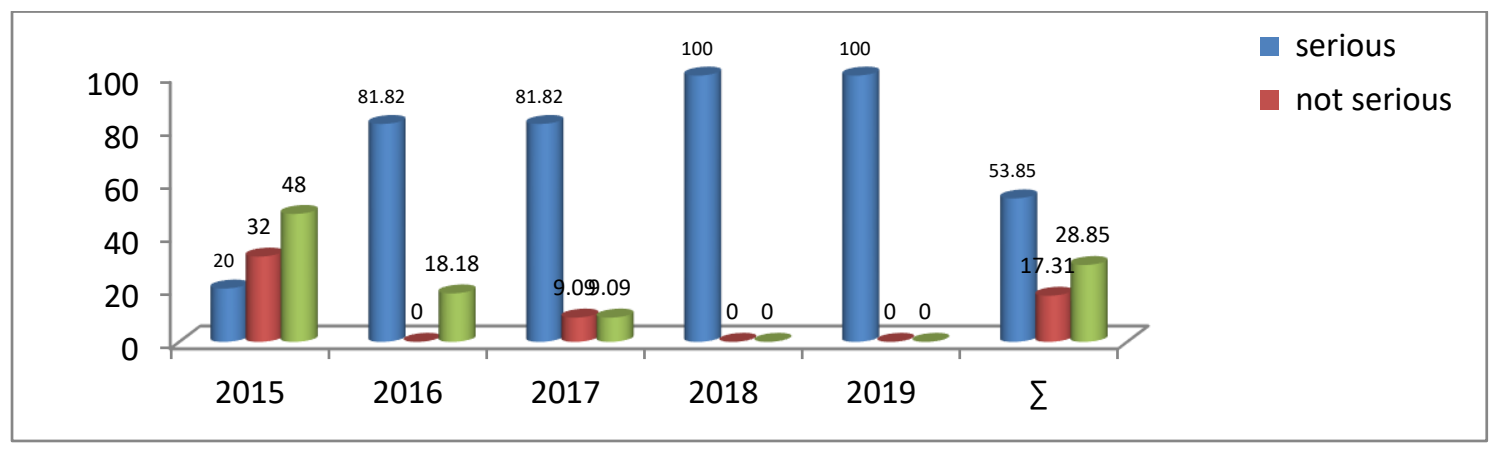

Figure 5 Percentage of Decision risk (\% serious,\% not serious and\% undecided) of excused samples during the period 2015-2019

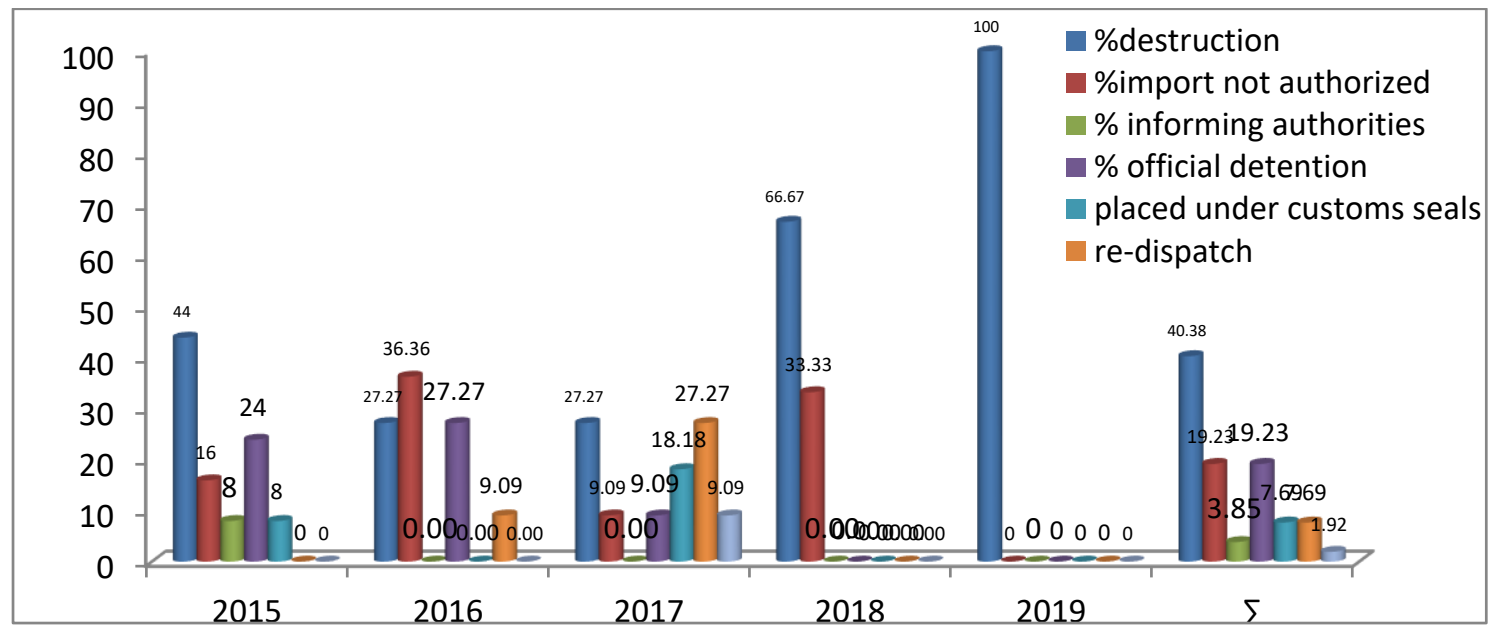

Figure 6 Percentage of action taken (destruction , import not authorized , informing authorities , official detention, , re-dispatch and placed under customs seals) of excused samples during the period 2015-2019

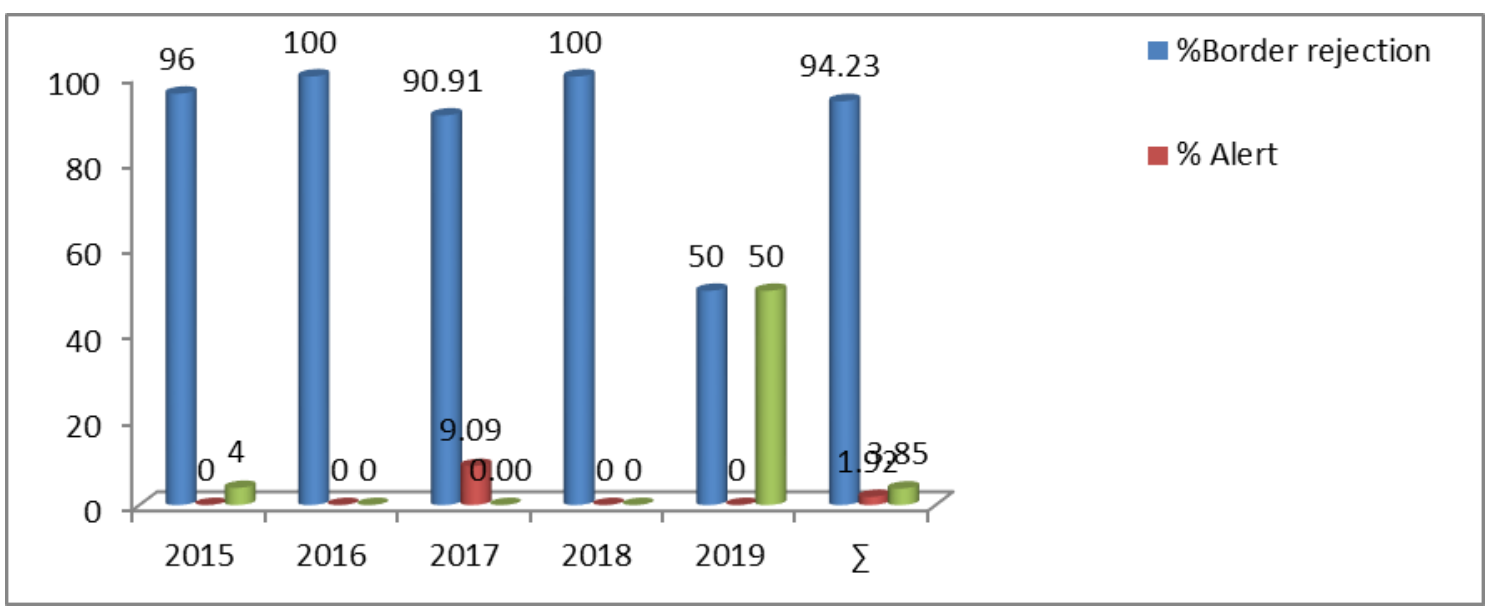

Figure 7 Percentage of notification type (border rejection, alert and information for attention) of excused samples during the period 2015-2019. 
Table 1 The number of violated Egyptian exports of vegetables samples, decision risk, action taken notification type, the range of detected pesticides in mg/kg, and the status of registration of each detected pesticide in Egypt in analyzed samples collected during 20015 to2019.

\begin{tabular}{|c|c|c|c|c|c|c|c|c|}
\hline Year & Commodity & $\begin{array}{l}\text { No.of } \\
\text { samples } \\
\text { violated }\end{array}$ & $\begin{array}{l}(*) \text { Decision } \\
\text { risk }\end{array}$ & $\left(^{*}\right)$ action taken & (*)notification type & Detected Pesticides & No. & $\begin{array}{l}\text { Registratio } \\
n \text { in } \\
\text { Egypt APC }\end{array}$ \\
\hline \multirow[t]{19}{*}{2015} & artichokes & 1 & (1) undecided & official detention(1) & border rejection(1) & Carbendazim & 1 & NR \\
\hline & cucumbers & 1 & (1) undecided & informing authorities(1) & $\begin{array}{l}\text { information } \\
\text { attention(1) }\end{array}$ & Procymidone & 1 & NR \\
\hline & \multirow[t]{2}{*}{ mix chillies } & \multirow[t]{2}{*}{1} & \multirow[t]{2}{*}{ (1) undecided } & \multirow[t]{2}{*}{ destruction(1) } & \multirow[t]{2}{*}{ border rejection(1) } & Oxamyl & 1 & R- NR1 \\
\hline & & & & & & Lambda-Cyhalothrin & 1 & R- NR1 \\
\hline & \multirow[t]{5}{*}{ peppers } & \multirow[t]{5}{*}{12} & \multirow[t]{2}{*}{ (6) undecided } & \multirow[t]{2}{*}{ informing authorities(1) } & \multirow[t]{5}{*}{ border rejection (12) } & Flusilazole & 6 & NR \\
\hline & & & & & & Carbendazim & 2 & NR \\
\hline & & & (4)serious & Destruction(6) & & Dinotefuran & 1 & R- NR1 \\
\hline & & & \multirow[t]{2}{*}{ (2) not serious } & \multirow{2}{*}{$\begin{array}{l}\text { official detention } \\
\text { (5) }\end{array}$} & & Dodine & 4 & R- NR1 \\
\hline & & & & & & Methomyl & 1 & R- NR1 \\
\hline & \multirow[t]{10}{*}{ strawberries } & \multirow[t]{10}{*}{10} & \multirow[t]{2}{*}{ (6) not serious } & \multirow[t]{2}{*}{ Destruction(4) } & \multirow{10}{*}{$\begin{array}{l}\text { border rejection } \\
\text { (10) }\end{array}$} & Fipronil & 1 & NR \\
\hline & & & & & & Cyfluthrin & 1 & R- NR1 \\
\hline & & & \multirow[t]{2}{*}{ (1)serious } & \multirow[t]{3}{*}{ import not authorized (4) } & & Dinotefuran & 1 & R- NR1 \\
\hline & & & & & & Methomyl & 2 & R- NR1 \\
\hline & & & \multirow[t]{6}{*}{ (3) undecided } & & & Propamocarb & 4 & R- NR1 \\
\hline & & & & \multirow{5}{*}{$\begin{array}{l}\text { placed under customs } \\
\text { seals (2) }\end{array}$} & & Propargite & 2 & NR \\
\hline & & & & & & Pyridalyl & 1 & NR \\
\hline & & & & & & Chlorpyrifos & 1 & R- NR1 \\
\hline & & & & & & Dimethoate & 2 & R- NR1 \\
\hline & & & & & & Oxamyl & 1 & R- NR1 \\
\hline$\sum$ & 5 & 25 & & & & 19 & & \\
\hline
\end{tabular}


GSC Advanced Research and Reviews, 2020, 05(01), 015-029

\begin{tabular}{|c|c|c|c|c|c|c|c|c|}
\hline \multirow[t]{15}{*}{2016} & fresh green beans & 1 & (1) undecided & official detention(1) & border rejection(1) & Propargite & 1 & NR \\
\hline & \multirow[t]{8}{*}{ peppers } & \multirow[t]{8}{*}{6} & \multirow[t]{5}{*}{ (5)serious } & import not authorised(1) & \multirow{8}{*}{$\begin{array}{l}\text { border rejection } \\
(6)\end{array}$} & Oxamyl & 3 & R- NR1 \\
\hline & & & & \multirow{2}{*}{$\begin{array}{l}\text { Destruction } \\
\text { (2) }\end{array}$} & & Methomyl & 1 & R- NR1 \\
\hline & & & & & & Oxamyl & 1 & R- NR1 \\
\hline & & & & \multirow{2}{*}{$\begin{array}{l}\text { official detention } \\
\text { (2) }\end{array}$} & & Lambda-Cyhalothrin & 1 & R- NR1 \\
\hline & & & & & & Propargite & 2 & NR \\
\hline & & & \multirow[t]{3}{*}{ (1) undecided } & \multirow[t]{3}{*}{ re-dispatch(1) } & & Chlorpyrifos & 2 & R- NR1 \\
\hline & & & & & & Carbendazim & 1 & NR \\
\hline & & & & & & Carbofuran & 1 & NR \\
\hline & \multirow[t]{6}{*}{ strawberries } & \multirow[t]{6}{*}{4} & \multirow[t]{6}{*}{ (4)serious } & \multirow{4}{*}{$\begin{array}{l}\text { import not authorized } \\
\text { (3) }\end{array}$} & \multirow{6}{*}{$\begin{array}{l}\text { border rejection } \\
\text { (4) }\end{array}$} & Methomyl & 3 & R- NR1 \\
\hline & & & & & & Profenofos & 1 & R- NR1 \\
\hline & & & & & & Propargite & 1 & NR \\
\hline & & & & & & Dimethoate & 1 & R- NR1 \\
\hline & & & & \multirow{2}{*}{$\begin{array}{l}\text { Destruction } \\
\text { (1) }\end{array}$} & & Oxamyl & 1 & R- NR1 \\
\hline & & & & & & Propargite & 1 & NR \\
\hline$\sum$ & 3 & 11 & & & & 15 & & \\
\hline \multirow[t]{10}{*}{2017} & cucumbers & 1 & (1)serious & re-dispatch(1) & border rejection(1) & Procymidone & 1 & NR \\
\hline & \multirow[t]{8}{*}{ frozen vine leaves } & \multirow[t]{8}{*}{3} & \multirow[t]{8}{*}{ (1) not serious } & \multirow[t]{8}{*}{ Destruction (1) } & \multirow[t]{8}{*}{ border rejection(1) } & Acetamiprid & 1 & R- NR1 \\
\hline & & & & & & Azoxystrobin & 1 & R- R1 \\
\hline & & & & & & Lambda-Cyhalothrin & 1 & R- NR1 \\
\hline & & & & & & Myclobutanil & 1 & R- R1 \\
\hline & & & & & & Propiconazole & 1 & R- R1 \\
\hline & & & & & & Carbendazim & 1 & NR \\
\hline & & & & & & Diniconazole & 1 & NR \\
\hline & & & & & & Flusilazole & 1 & NR \\
\hline & tomatoes & 3 & (3)serious & official detention(1) & Alert(1 & Chlorpyrifos & 3 & R- R1 \\
\hline
\end{tabular}


GSC Advanced Research and Reviews, 2020, 05(01), 015-029

\begin{tabular}{|c|c|c|c|c|c|c|c|c|}
\hline & & & & Destruction (1) & border rejection(2) & & & \\
\hline & & & & $\begin{array}{l}\text { placed under customs } \\
\text { seals(1) }\end{array}$ & & & & \\
\hline & strawberries & 1 & (1) undecided & import not authorised(1) & border rejection(1) & Methamidophos & 1 & NR \\
\hline & peppers & 5 & (5)serious & re-dispatch (2) & border rejection(5) & Methamidophos & 1 & NR \\
\hline & & & & & & Propargite & 4 & NR \\
\hline & & & & & & Methomyl & 1 & R- NR1 \\
\hline & & & & Destruction (1) & & Chlorpyrifos & 2 & R- NR1 \\
\hline & & & & $\begin{array}{l}\text { placed under customs } \\
\text { seals (1) }\end{array}$ & & Propiconazole & 1 & R- NR1 \\
\hline & & & & & & Chlorfenapyr & 1 & R- NR1 \\
\hline & & & & & & Lambda-Cyhalothrin & 1 & R- NR1 \\
\hline & & & & return to consignor & & Flusilazole & 1 & NR \\
\hline & & & & (1) & & Carbofuran & 1 & NR \\
\hline$\sum$ & 5 & 11 & & & & 20 & & \\
\hline 2018 & peppers & 3 & (1)serious & import not authorized & border rejection(3) & Carbofuran & 1 & NR \\
\hline & & & & (1) & & Chlorpyrifos & 1 & R- NR1 \\
\hline & & & & Destruction (2) & & Methomyl & 1 & R- NR1 \\
\hline$\sum$ & 1 & 3 & & & & 3 & & \\
\hline 2019 & peppers & 1 & (1)serious & Destruction(1) & Information & Propargite & 1 & NR \\
\hline & & & & & attention(1) & Chlorpyrifos & 1 & R- NR1 \\
\hline & & & & & & Propargite & 1 & NR \\
\hline & strawberries & 1 & (1)serious & Destruction(1) & border rejection(1) & Oxamyl & 1 & R- NR1 \\
\hline$\sum$ & 2 & 2 & & & & 4 & & \\
\hline Total & 16 & 52 & & & & 61 & & \\
\hline
\end{tabular}

APC $=$ Agriculture Pesticide Committee, R= Registered, R1= Recommended, NR= Not Registered, NR1= Not Recommended; $\left({ }^{*}\right)$ : Frequency 


\subsection{Pesticides detected in Egyptian exports of vegetables for the period 2015-2019, based on the RASFF database, their Toxicological class, main groups, and registration situation in Egypt}

\subsubsection{Evaluation by pesticides}

\subsubsection{Detected pesticides groups}

Data in (Table 2 and Fig .8) show that 24 pesticide active ingredients were detected in Egyptian exports of vegetables for the period of 2015-2019, based on the RASFF database. Propargite was the most contaminant in the studied samples followed by chlorpyrifos, methomyl, flusilazole, oxamyl and carbendazim and their percentage frequencies were $(14.46 \%, 12.05 \%, 10.84 \%, 9.64 \%, 7.23 \%$ and 6.02\%), respectively. While the lowest pesticide active ingredients were diniconazole, myclobutanil, azoxystrobin, acetamiprid, dinotefuran, profenofos, fipronil, cyfluthrin, chlorfenapyr and pyridalyl and their percentage frequency was $1.2 \%$.

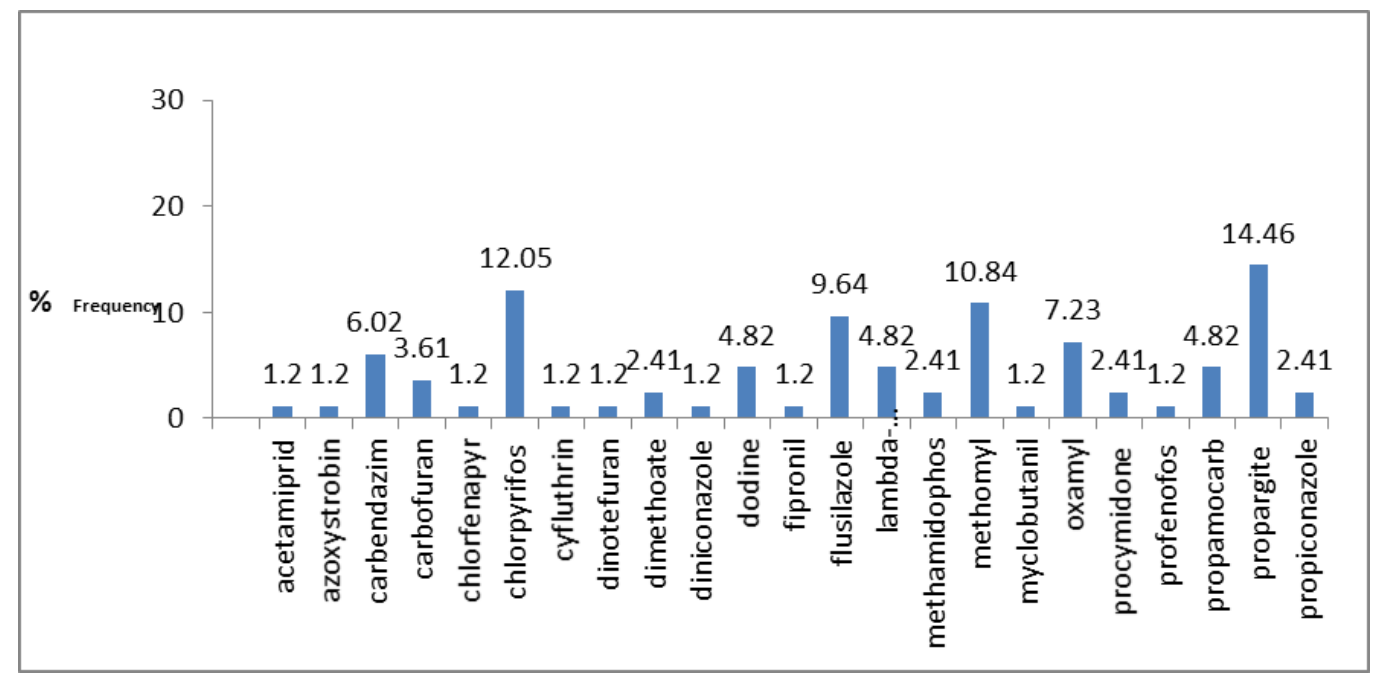

Figure 8 Frequency percentages of most detected pesticide residues in Egyptian exports of vegetables samples for the period 2015-2019, based on the RASFF database

\subsubsection{Detected chemical classes}

According to (WHO 2009/2010) about 33.33\% ( 8 out of 24) of the pesticides used belonged to the World Health Organization (WHO) toxicity class II (moderately hazardous), followed by WHO toxicity class III (slightly hazardous) and WHO toxicity class U (Unlikely to pose an acute hazard in normal use) showed, 20.8\% (5 out of 24), with a few $16.64 \%$ under toxicity class Ib (highly hazardous) and WHO toxicity class NC (Not classified) was $8.32 \%$. (Table 2 and Fig. 9).

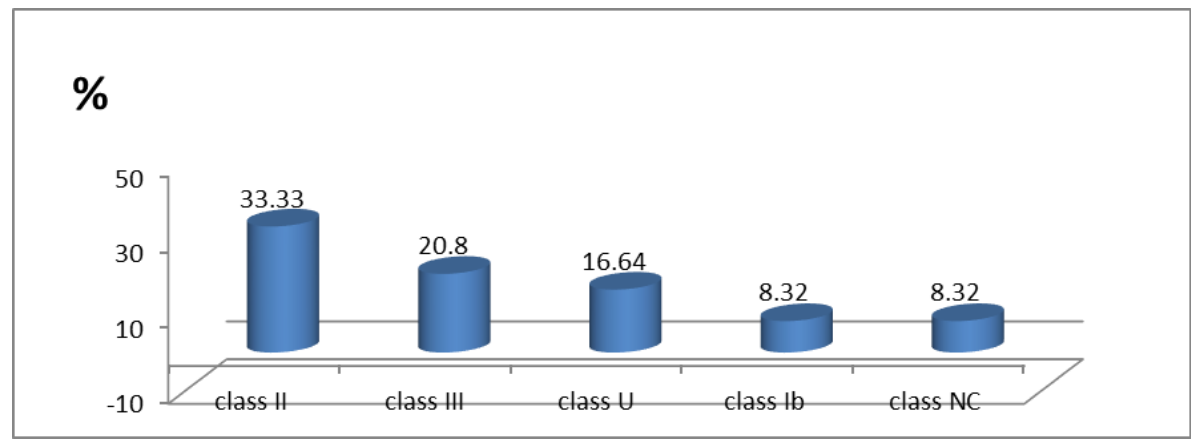

Figure 9 The percentage of detected pesticide residues based on pesticide to the World Health Organization (WHO) toxicity classification in Egyptian exports of vegetables samples for the period 2015-2019, based on the RASFF database

Data in (Table 2 and Fig.10) show that about 50\% (12 out of 24) of the pesticide active ingredients belonged to insecticides were detected in Egyptian exports of vegetables for the period 2015-2019, based on the RASFF database, 
followed by fungicides (37.5\%), and acaricides (8.32\%). while pesticide active ingredients had two uses such as :nematicides + Insecticides were 4.16\%. All Egyptian exports of vegetables samples for the period 2015-2019, based on the RASFF database (51 samples) were free from any detectable residues of herbicide active ingredients. (IUPAC 2003/2004).

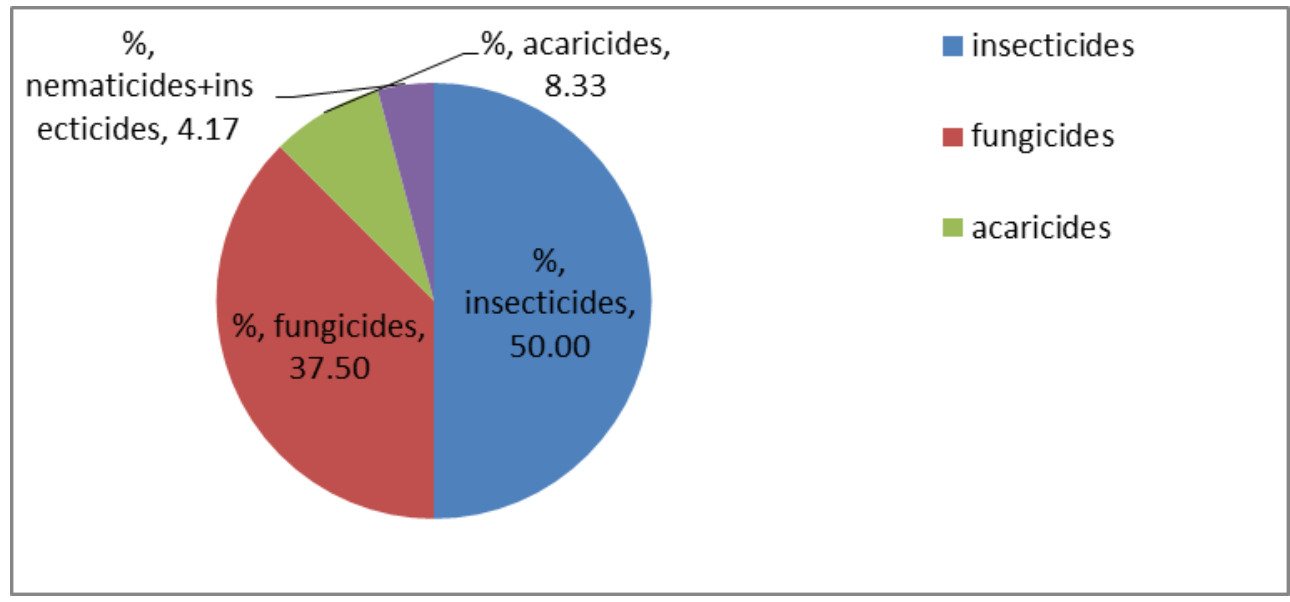

Figure 10 The percentage of detected pesticide residues based on pesticide use classification in Egyptian exports of vegetables samples for the period 2015-2019, based on the RASFF database

Results in (Table 2 and Fig.11) indicate that, about 20.83\% (5 out of 24) of the pesticides used belonged to carbamate group, followed by organophosphate group and conazole (triazoles) group 16.64\%, while Neonicotinoid group and pyrethroid group were $8.32 \%$. On the other hand, different groups recorded less than $4.16 \%$ such as aliphatic nitrogen, dichlorophenyldicarboximide, methoxyacrylate, strobilurin, phenylpyrazole, pyrrole, sulfite ester, and unclassified (IUPAC 2003/2004).

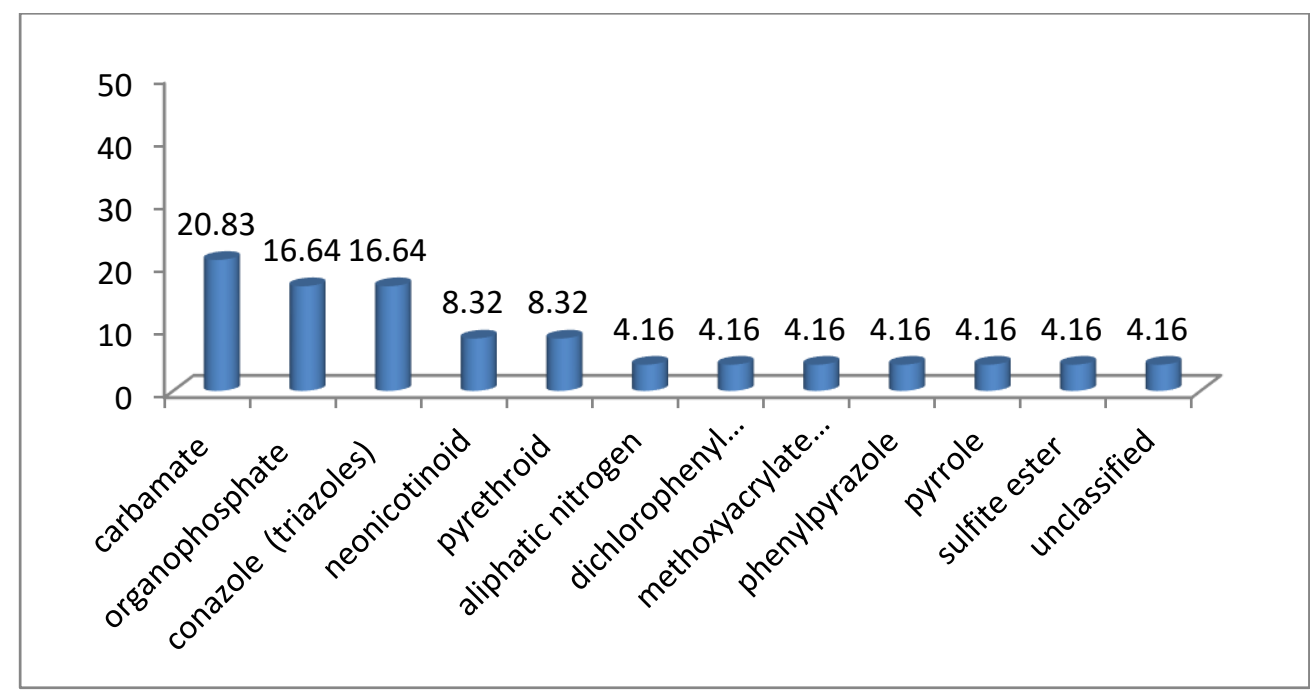

Figure 11 The percentage of detected pesticide residues based on pesticide groups classification in Egyptian exports of vegetables samples for the period 2015-2019, based on the RASFF database.

\subsubsection{APC implementation}

The Agricultural Pesticide Committee, referred herein as APC, is the sole statutory agency responsible for registration, handling, and use of agricultural pesticides in the Arab Republic of Egypt. The committee issued the recommendation of registered pesticides for each crop (APC 2020).

Pesticides divided according to their position for registration as registered pesticides, unregistered pesticides, forbidden pesticides and restricted use pesticides. 
(Table 2 and Fig.12) shows that 14 out of 24 active ingredients registered in the state of Egypt with the percentage value of $58.33 \%$, while the percentage of restricted use pesticides was $8.32 \%$. In addition, the percentage of not registered pesticides was $33.33 \%$. All pesticides (24 active ingredients) detected in Egyptian exports of vegetables for the period 2015-2019, based on the RASFF database, were free from any Forbidden pesticides.

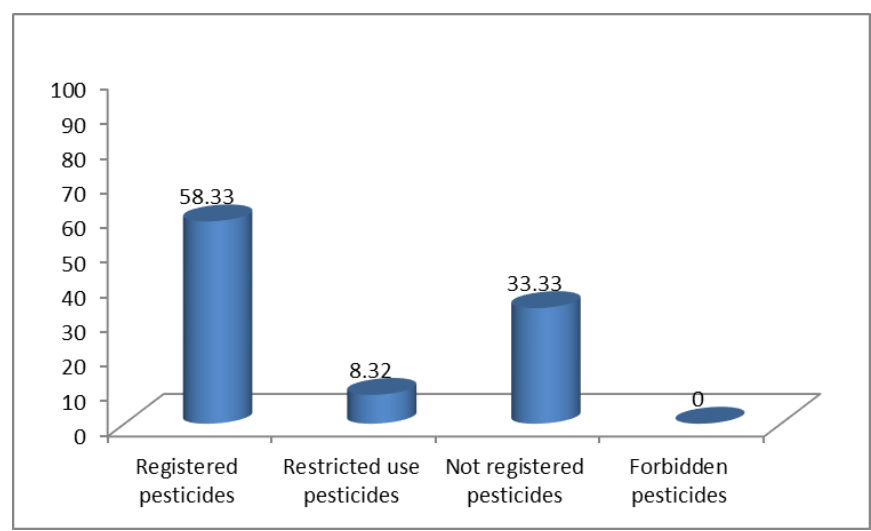

Figure 12 The frequencies (\%) of registered, restricted use pesticides, Nonregistered and Forbidden in Egyptian exports of vegetables samples for the period 2015-2019, based on the RASFF database

The obtained findings are in agreement with those obtained by (Leuschner et al. 2013; Gad Alla et al. 2013; Gad Alla et al. 2015; RASFF 2015- 2019; Lüth et al. 2019 ; Postolache et al. 2020).

Table 2 Classification of pesticides, frequency, percentage frequency and their toxicological class, main groups and registrationsituation of pesticides detected in Egyptian exports of vegetables for the period 2015-2019, based on the RASFF database.

\begin{tabular}{|l|l|l|l|l|l|l|}
\hline $\begin{array}{l}\text { Active } \\
\text { Ingredient }\end{array}$ & $\begin{array}{l}\text { Frequen } \\
\text { cy }\end{array}$ & $\begin{array}{l}\mathbf{\%} \\
\text { Frequen } \\
\text { cy }\end{array}$ & $\begin{array}{l}\text { WHO } \\
\text { Toxicity(a*) }\end{array}$ & Main group & Use & $\begin{array}{l}\text { Registratio } \\
\text { nsituation } \\
\text { (b**) }\end{array}$ \\
\hline acetamiprid & 1 & 1.20 & II & neonicotinoid & insecticides & R \\
\hline azoxystrobin & 1 & 1.20 & U & $\begin{array}{l}\text { methoxyacrylatestrobil } \\
\text { urin }\end{array}$ & fungicides & R \\
\hline carbendazim & 5 & 6.02 & U & carbamate & fungicides & NR \\
\hline carbofuran & 3 & 3.61 & Ib & carbamate & $\begin{array}{l}\text { nematicides+insectic } \\
\text { ides }\end{array}$ & NR \\
\hline chlorfenapyr & 1 & 1.20 & U & pyrrole & acaricides & R \\
\hline chlorpyrifos & 10 & 12.05 & II & organothiophosphate & insecticides & RUP \\
\hline cyfluthrin & 1 & 1.20 & II & pyrethroid & insecticides & R \\
\hline dinotefuran & 1 & 1.20 & NC & neonicotinoid & insecticides & R \\
\hline dimethoate & 2 & 2.41 & II & organothiophosphate & insecticides & R \\
\hline diniconazole & 1 & 1.20 & III & conazole (triazoles) & fungicides & NR \\
\hline dodine & 4 & 4.82 & III & aliphatic nitrogen & fungicides & R \\
\hline fipronil & 1 & 1.20 & II & phenylpyrazole & insecticides & NR \\
\hline flusilazole & 8 & 9.64 & III & conazole (triazoles) & fungicides & NR \\
\hline $\begin{array}{l}\text { lambda- } \\
\text { cyhalothrin }\end{array}$ & 4 & 4.82 & II & pyrethroid & insecticides & R \\
\hline $\begin{array}{l}\text { methamidop } \\
\text { hos }\end{array}$ & 2 & 2.41 & Ib & organothiophosphate & insecticides & NR \\
\hline methomyl & 9 & 10.84 & Ib & carbamate & insecticides & R \\
\hline myclobutanil & 1 & 1.20 & III & conazole (triazoles) & fungicides & R \\
\hline oxamyl & 6 & 7.23 & Ib & carbamate & insecticides & R \\
\hline
\end{tabular}




\begin{tabular}{|l|l|l|l|l|l|l|}
\hline procymidone & 2 & 2.41 & U & $\begin{array}{l}\text { dichlorophenyldicarbo } \\
\text { ximide }\end{array}$ & fungicides & NR \\
\hline profenofos & 1 & 1.20 & II & organothiophosphate & insecticides & RUP \\
\hline propamocarb & 4 & 4.82 & U & carbamate & fungicides & R \\
\hline propargite & 12 & 14.46 & III & sulfite ester & acaricides & NR \\
\hline $\begin{array}{l}\text { propiconazol } \\
\text { e }\end{array}$ & 2 & 2.41 & II & conazole (triazoles) & fungicides & R \\
\hline pyridalyl & 1 & 1.20 & NC & unclassified & insecticides & R \\
\hline
\end{tabular}

$\left(\mathrm{a}^{*}\right)$ : Ib: Highly hazardous; II: Moderately hazardous; NC: Not classified;III: Slightly hazardous;U: Unlikely to pose an acute hazard in normal use; $\left(b^{* *}\right)$ : R: Registered; NR: Not registered; F: Forbidden; RUP : Restricted use pesticides

\section{Conclusion}

The present study showed high percentages of application of non-recommended pesticides on particular vegetables in addition of presence of not registered pesticides in vegetables samples.

To prevent exposure to pesticides, it is necessary to reduce and control the use of pesticides in different commodities by enforcement activities. It also calls for improved residue control of production, tighter regulation of pesticide spraying and tighter regulation on the sale of pesticides as well as for education of farmers and the implementation of integrated pest management system. Nevertheless, monitoring programs are increasingly important and essential to ensure minimal pesticide residue levels in food.

\section{Compliance with ethical standards}

\section{Acknowledgments}

I would like to express special thanks to The Agricultural Pesticide Committee (APC) of the Arab Republic of Egypt for providing me with RASFF notifications from their database and enclosed documents.

\section{References}

[1] Abd-El Rahman, T.A , Fayza A. S, and Amany R. M . Dietary Intake of Pesticides Based on Import Animal Liver Consumption: A Case Study, Cairo, Egypt. International Journal of Innovation and Applied Studies 2016. Vol. 17 No. , pp. 424-431.

[2] (APC) Agricultural Pesticide Committee2020. http://www.apc.gov.eg/en/default.aspx

[3] Attallah RE. Validation of multi residue method for determination of 200 pesticide residues in fresh pepper using GC-MS/MS. Current Science International. 2016.05(03): 276 -285.

[4] Attia GM. Optimum geographic distribution of Egyptian exports of main vegetable crops. Egypt. J. Agric. Res. 2016.. 94 (4): 1067-1087.

[5] EFSA 2008-2010 Annual report on pesticide residues according to article 32 of regulation (EC) No 396/2005. EFSA Journal, 8(6), 1646.

[6] EFTA Surveillance Authority, https://www.eftasurv.int/EU

[7] Pesticide residue MRL database. Regulation (EC) No 396/2005.

[8] EU Rapid Alert System for Food and Feed (RASFF) portal https://webgate.ec.europa.eu/rasffwindow/portal/?event=SearchForm\&cleanSearch=1

[9] European Food Safety Authority, https://www.efsa.europa.eu/

[10] Fernndez-Alba AR, Garca-Reyes JF. Large-scale multi-residue methods for pesticides and their degradation products in food by advanced LC-MS. Trac-Trend. Anal. Chem. .2008 .27 (11): 973-990.

[11] GOEIC 2020. Foreign Trade Data Warehouse -General Organization for Export and Import Control. https://www.goeic.gov.eg/ar/search/default/index/q/ 
[12] Eu Pesticides database https://ec.europa.eu/food/plant/pesticides/eu-pesticidesdatabase/public/?event=homepage\&language $=\mathrm{EN}$

[13] Rasff Rapid Alert System for Food and Feed . http://ec.europa.eu/food/safety/rasff/index en.htm

[14] IUPAC 2003/2004. International Union of Pure and Applied Chemistry http:/ /sitem. Herts .ac. uk/aeru/ iupac/115.htm.

[15] Gad Alla SA ,Ayoub MM. ; Amer MA , Thabet WM . Dietary Intake of Pesticide Residues in some Egyptian Fruits. Journal of Applied Sciences Research. 2013. 9(1): 965-973.

[16] Gad Alla SA; Almaz MM.; Thabet WM , Nabil MM .Evaluation of Pesticide Residues in some Egyptian Fruits. International Journal of Environment. 2015 .04: 87-97.

[17] Leuschner RGK, Hristova TRM. The Rapid Alert System for Food and Feed (RASFF) database in support of risk analysis of biogenic amines in food .Journal of Food Composition and Analysis. 2013. 29:37-42.

[18] Lüth .S, Boonea I, Kletaa S, Sascha D. Analysis of RASFF notifications on food products contaminated with Listeria monocytogenes reveals options for improvement in the rapid alert system for food and feed. Food Control; 2019.96:479-487.

[19] Ministry of Agriculture, A.R.E. 2020. Pest Control Programme (in Arabic ). pp: 80-87.

[20] Postolache ASG ,Adinami E, , Chelmu.SS, Aritonam, Ciorpac M, POP. C, CiobanuI MM, Creangă. Ș. Analysis of RASFF notifications on contaminated dairy products from the last two decades: 2000-2020. Rom Biotechnol Lett. 2020.25(2): 1396-1406.

[21] RASFF The Rapid Alert System for Food and Feed - 2016 http://ec.europa.eu/food/safety/rasff/index_en.html

[22] RASFF The Rapid Alert System for Food and Feed - 2019 http://ec.europa.eu/food/safety/rasff/index_en.html

[23] WHO recommended classification of pesticides by hazard and guidelines to classification - 2009. 2010 pp.78 